\title{
The Logical Discipline of Normative Argumentation. Some considerations on the axiological status of speech acts
}

\author{
Jan Wawrzyniak \\ Institute of Linguistics, Adam Mickiewicz University \\ ul. Międzychodzka 5, 60-371 Poznań \\ jawa@amu.edu.pl
}

\begin{abstract}
This paper is intended to promote a way of is-ought derivation, rooted in neonaturalistic solutions which were worked out within the scope of both the ontology of values and meta-ethical applications of 20th Century linguistic philosophy. Normative, especially in the sphere of morality, reasoning is supposed to be the most significant component of the structure of social communication. The common practices of normative persuasion employ a variety of modes of argumentation, such as the usage of evaluations, norms, imperatives, performative utterances, prescriptions, and optatives. There is a wide range of kinds of emotive pressure produced by speech acts, behind which some intentions of perlocutionary effects are hidden, and which all have methodologically differentiated status. Therefore, the ability to recognize some tricks employed in such practices, as well as the qualified faculty of argumentation for and validation of one's own moral convictions seems to be an indispensable component of a subject's high cultural competency. The moral responsibility for social states-of-affairs generated by speech acts requires such competency. The neonaturalistic approach - itself representing cognitive meta-ethics and recognizing the pragmatic functions of speech acts as a social phenomenon - proposes a philosophical alternative to the cage of formalized languages (like various systems of deontic logic) for normative reasoning in order to find real, verifiable - not necessarily of contractual origin value-referred premises for the inference of socially applied judgments of duty. The distinction between logical validation and moral (value-referred) justification of imperatives is emphasized at the same time. On this account certain philosophical interpretations of the categories of "fact", "value" and "personal agent of valuation and cognition" are carried out and an example of is-ought inference is presented.
\end{abstract}

\section{The semiotics of the problem}

My initial question concerns the purpose of normative discourse, where the "normative" can mean (i) discourse employing evaluative statements, appraisals, judgments of duty, norms, orders, prohibitions, prescriptions etc; (ii) "referred to values"; (iii) "referred to a socially -set -up benchmark or pattern". Can the purpose be supposed as being, e.g., truth, social agreement on what should be done, the determination of records of differences of opinions, rightness, or the efficiency of social influence effected by means of the speech act? From the perspective of meta-ethics, comprehended as the hermeneutics of normative discourse - both common and professional (i.e. as the language as well as argumentation employed within theoretical-ethical deliberations) - 
there are two distinctive opposite interpretations about what the discourse really is, or what it consists in: the cognitive and non-cognitive ones. Naturalism used to be indicated as an example of the former, and emotivism as an example of the latter.

The cognitive standpoint claims that our discussions or quarrels within the normative spheres of social consciousness and practice - like morality - aim at the determination of the truth/falsity of is-statements (like evaluations) or rightness/wrongness of ought-propositions. On the contrary, non-cognitivism interprets our moral discourse not as a dispute about truth but as an intentional strategic and performative play. We don't really want to convince anybody that a given state-of affairs or human action was good, wrong, noble or nasty, at all; instead we want to force our convictions and approvals/disapprovals on others and to implant in them emotions similar to ours, and finally make them behave as we want them to. In other words, it is an opposition between semantic and pragmatic interpretations of the discourse then. The truth, requiring a definite methodological discipline to be determined, is the main value which the cognitivists aim at, while the social efficiency of speech acts, operating with normative utterances, is the purpose of the non-cognitivists. What is more important then: truth or social effect?

An act of communication (especially discussion) can be understood as a kind of social action which is aiming at perlocutive consequences. Speech acts make for social interactions and pressure, so it apparently seems that the pragmatic perspective and practice of argumentation does not require any special logical discipline in order to be conducted in a socially effective way. Can we then put aside the fundamental logical problem of the is-ought distinction and say that any argument (including a nonverbal one) is correct and acceptable if it can make someone do what someone else wants? Is it methodologically as well as morally acceptable to employ any persuasive way of moving from the Is to the Ought in order to make others - by means of words - behave as we prefer?

Meta-ethical neonaturalism claims that the contrary is the case: the logical correctness (formal validity) of normative reasoning (justification) is the crucial condition for this reasoning to be socially accepted and, as such, causing a performative effect. This is the logical correctness of a reasoning that makes any arguments employed convincing and socially effective in inducing human conduct. The logical correctness of argumentation seems to be the best instrument for generating perlocutive effects, or the best persuasive agent in social action by means of language. The methodologically correct determination of truth or rightness of a normative statement makes the best pragmatic factor for the statement being socially acceptable by sufficiently educated participants in normative discourse, respecting the rules of rationality being a necessary condition of a functional social cooperation. It must be remembered, however, that the logical correctness of reasoning itself does not determine the epistemic status (e.g. material truthfulness) either of premises or conclusions.

\section{The introduction of the neonaturalistic perspective}

From the radical neonaturalistic perspective, as I identify my standpoint, I would like to prove that a logically correct passage from "is" to "ought" is possible, and even better justified than well known J. Searle's solution, thanks to philosophical operations performed on the categories of "fact", "value" and "subject (agent) of valuation as well as cognition. Neonaturalism recognizes both the category of truth/falsity as attributable to normative is-propositions (like evaluations) and rightness/wrongness to ought-conclusions (norms, orders). In order to construct logically proper and verifiable/falsifiable argumentation that does not commit the naturalistic fallacy, it is necessary both to find an ontological possibility for an empirical fact to be a normative one and to make the participants of a discourse abstract ${ }^{1}$; also a set of transcendental (pan-individual as well as pan-specific) values that can underlie the methodologically proper attribution of rights as well as duties to entities making up the universe of valuation (axiosphere) becomes an aim

\footnotetext{
${ }^{1}$ For the main ideas and terminology of radical neonaturalism see: (Wawrzyniak 2000)
} 
of philosophical investigation. Neonaturalistic ontology does away with the dichotomous division of reality into spheres of values and facts. Values can be made actual provided that they are understood as empirical facts.

If we want to remain faithful to methodological requirements that D. Hume, G.E. Moore, and I. Kant forced on acceptable normative reasoning, we cannot fail to work out models of correct <is - ought> argumentation. One of them is the application of a system of deontic logic as a special language in which we conduct our reasoning; the second approach - represented by J. Searle is such a reinterpretation of the premises of normative reasoning, as well as the layers and functions of speech acts, which would allow us to derive an ought-conclusion from the set of is-premises; the third way, promoted by radical neonaturalism, is based on some typically philosophical solutions ${ }^{2}$.

John Searle was trying, on the basis of J. Austin's philosophy of language, to prove that the is - ought derivation is possible within the universe of linguistic (logical) operations themselves. My proposal suggests that the derivation (justification) of normative conclusions, i.e. a reasoning starting with certain is-statements about what the world is like and ending with ought-conclusions about what human activity within it should be like, is possible thanks to reference to the ontology of values - and not only to the intrinsic coherency of linguistic operations - as to a benchmark for the main premises of normative reasoning.

\section{Being and Oughtness}

The traditional understanding of the distinction between "being" (resp. a fact) and "oughtness" (resp. a value) implies the mode of existence of a value as a pure obligation, which makes this category inconsistent: a valued state-of-affairs is supposed to be a value provided it is never actualized as a fact $^{3}$. So, values get the paradoxical status of non-beings. The more, claiming that values are ex definitione metaphysically alien to facts is committing the fallacy of petitio principi as well. From the neonaturalistic perspective, the ontological modality of a state-of-affairs being a value does not consist in the meta-oughtness of its being the non-fulfilled obligation to be actualized, but the modality consists in the obligation for the state to come into real existence. Duty (resp. a norm) can only be derived from being, or from the empirical fact that a given state-of-affairs has been valued. Values have the status of real processual states-of-affairs, but not autonomous substances.

Neonaturalism neither reduces axiological qualities to empirical ones nor derives moral judgments from the statements of non-moral facts, but it proposes the ontological interpretation of normativity (value-status) of empirical facts. The normative states-of-affairs do not exist in a non-empirical way and only the empirical can become the normative. The status of being a value is a particular normative way (valuableness) of the proceeding of an empirical fact ${ }^{4}$.

\footnotetext{
2 The well known and widely discussed example of such a scheme of normative reasoning we owe to J. Searle; see (Searle 1969: 175-198) and (Hare 1967). It should be noted that J. Searle, S. Toulmin and $\mathrm{Ph}$. Foot, who initiated argument about the dogma of post-Wittgenstein linguistic philosophy that the meaning of an expression can be identified with its usage, were the pioneers of the moderate neonaturalistic trend in meta-ethics (Wawrzyniak, 2000: 21-22)

${ }^{3}$ For the understanding of the terms „,valued”, „valuable”, "value-able”, "value-ability”, “valuability”, see (Wawrzyniak 2000: 221-227)

${ }^{4}$ Value is an ontic category whereas valuableness is an ontological one. Values are unstable relational statesof-affairs, going on in time and composed of an actively valuing subject (a valuer), a valued object (that can be a living creature as well), and a relation (ontic interdependence) between them; this is every relation in which the subject wishes or does not wish - in result of valuation which is a sui generis emotional and instinctive experience - to find itself with the object (or with a state he want/does not want to participate in). The living source of valuation is an internal constitutive element of a value. Valuation itself creates valuableness (positive or negative), but not the physical existence of a value. The actualization of valued states-of-affairs is not identical with valuation but is induced by it. But the real existence itself of anything does not make this valued. If a factually existing material set becomes valued (and called a value), its physical (ontic) status does not change; it does not acquire any new objective properties, however it becomes non-indifferent to the subject that reacts toward this set with a valuation act.
} 
In neonaturalism, a difference between "being" and "oughtness" is interpreted as the difference between the actual and intentional-prospective existence of a valued state-of-affairs. The neonaturalistic ontology makes it possible to drive "duty" (norms) from "being" (is-statements) because it identifies the value with the state of actual being and recognizes the valuableness (normativity) of physical being as such. There is no oughtness beyond the empirical world, and there exists only one reality of facts, among which some are valued. The very process of making an intentional valued state-of-affairs actual, or the process of fulfilling an obligation, is - as an element of axiological situation - a valued fact, and the oughtness of being (lasting) of an intended value does not vanish together with its actualization ${ }^{5}$.

The axiological non-indifference of the empirically experienced reality provides for the necessary condition of a reasonable formulation of normative postulates. Indeed, we used to postulate for either a change (in case of devaluation) or preservation (while valuation is positive) of the hitherto proceeding states of empirical reality which are non-indifferent to us. It is a fallacy to conclude a norm from the statement of a non-normative fact, but not on the basis of an evaluation, which as such, is an is-proposition, denoting approvals/disapprovals of a state-of-affairs on account of which existence the norm (to change or to preserve) is formulated.

If ethics is to change the world efficiently, it must both act within the framework of the world's nomological order and treat the factual as valuable. Without the identification of the normative with the factual (resp. the relativization of norms to given facts taken as a values) any discourse that employs norms, evaluations, orders, prescriptions, persuasions - especially ethical - makes no sense. Our wishes and ideas assume real axiological indifference to a state-of-affairs to which they propose any alternatives. And without the "location" of a source of valuation within the structure of a value, empirical facts would remain purely non-axiological, to which normative qualities would have to be "attached" from a different universe. And if the source had no subjective-personal status, the preformed values-in-themselves would remain noncommittal to any subject which, therefore, would merely have the status of an external observer ${ }^{6}$. The norm, or a judgment articulating oughtness, is a consequence of the non-indifference (approval/disapproval) of a living valuer towards the state-of-affairs within which this valuer has found itself?

Valuableness of a value, actively conferred on the world by creatures able to value, is the relation of sui generis emotional non-idifference of a valuer toward a particular configuration of empirical qualities, and not a passive reception of separate value-entities. The correlation of certain configurations with valuing reactions, which motivate behavior, is teleonomic (adaptively functional) and these configurations are key stimuli in releasing valuation. Innate valuational adjustment of organisms to configurations such as vital values, or the attributes as well as necesary conditions to be a living being, are motivations inducing the defense of these values. Instinctive (apetitive-consumatory), reactional (relational) status of valuation constitutes the state of axiolocation, in which organisms must remain while fighting for survival. They scour the environment for the natural stimuli releasing valuation. Axiolocation make it possible for them to get oriented in the environment and creates a real hierarchy of importance among its elements. Axiological reactivity is an attribute of the cognitive activity of organisms in the environment; see (Wawrzyniak 2000: 21, 93-101, 180-183).

${ }^{5}$ For the notion of axiological (normative) situation see: (Wawrzyniak 2000: 175-176).

${ }^{6}$ In neonaturalistic axiology, the active agent of valuation as well as cognition is the evolutionary transcendental (panspecific) subject (valuer)- TS - or Living Being as such. This abstract category represents the biocommunity of values. TS is the exclusive and complete source of valuation, and owing to TS there exists only one naturally valued world. Values are actualized and reproduced by TS, of whose value-ability has emerged in the evolutionary process of natural selection. The category of TS - as an ontological as well as normative construction - enables us to meet methodological standards (e.g. the open question argument, which ethical notions are subject to, as well as the universalizability of ought-statements) that G. E. Moore, D. Hume, and I. Kant addressed to ethical claims. Mutual understanding within the realm of values, and thus within the cultural space of communication (interpersonal, social, intercultural and interspecific, verbal as well as nonverbal), is possible due to the biocommunity - embodied by the TS - of the codes of axiological reactions; see (Moore 1956: ch. I-II, IV), (Wawrzyniak 2000: 20-21, 205-211).

${ }^{7}$ A given value is always meta-valued positively in relation to less or not accepted alternatives, and this value is, during the period of its proceeding, becoming meta-valued negatively in relation to more preferred 


\section{Naturalistic Fallacy and Naturalistic Fallacy Fallacy}

In the presented version of meta-ethical neonaturalism - which is more radical than J. Searle's position expressed in his Speech Acts - some judgments of valued brute facts provide for necessary normative premises of ought-conclusions. If we assume that values are, by definition, what should (resp. should not) be, then the existential judgments of values (judgments finding the existence of valued brute facts), which as such are is-statements, can serve as necessary normative premises (obligation-premises) in the derivation of duty orders or prescriptions. The evaluative statement, or the evaluation proper, presupposes an existential value-judgment. In the procedure of justification of normative conclusions they logically function as two different judgments; however both of them are crucial to validate a norm of human conduct. The evaluative statement qualifies the identified valued state-of-affairs as positive or negative. The judgment of value is necessary in order to infer a norm in general, whereas an evaluation statement determines whether a norm is a prohibition or an order. The oughtness-related premises of ethical norms are, therefore, the conjunctions of existential-value judgments and evaluative statements (classifying the identified valued facts as positive or negative). Prohibitions and orders are the logical and practical consequences of the identification of a valued (positively or negatively) state-of-affairs which they refer to; in practice, however, they can also be justified in the so-called thetic way, i.e. on account of the very fact of their being institutionally set up and introduced ${ }^{8}$.

Some brute facts are, at the same time, institutional and linguistic ones (e.g. promises), and the binding status of certain speech acts (especially performative utterances) does not result either from grammar or logic but from the very social fact of these acts being arisen, i.e. of the usage of statements of definite content. The axiological character of the "institution" of promising (committing oneself) as well as keeping one's promises is a brute social fact. In the well known Searle's argumentation, already the very brute fact of a promise being voiced, which is a locution denoted by the first premise of the argumentation, is axiologically relevant; however it is not an institutional fact yet ${ }^{9}$. The promise is the performative utterance and - as a normative illocution - can only be actualized in an extra-verbal context, and its axiological status comes from the brute social fact of its coming into existence ${ }^{10}$. A normative as well as linguistic fact of promising is the ought-consequence of a valuableness of a state-of-affairs (a value in spe) that is being promised. The locution of promise ought to be performed because what is being promised ought to be promised.

An institutional fact is not always justified in an axiological way (i.e. by the reference to values). The acts of administrative decisions create the type of thetic norms, of which binding power can be questioned by the reference to values which are alternative ones in relation to the values which are implicitly hidden behind these norms. Neither an act itself of the determination of a norm nor a fact of its common observance can be axiologically (morally in particular) obligatory to an addressee of this norm; and, at the same time, a fact that a given type of human conduct is not forbidden by law does not mean that this conduct is morally acceptable. From the other side, the status of being a value, attributed to certain institutional facts, does not result from their being institutional. Health is a value not because it is legally protected, but it is protected because it is a brute valued fact. The attribution of axiological status exclusively

alternatives. The fact that what is really existing is being unaccepted - in relation to its alternatives and it should not exist longer does not mean that it is not a value any more. It is quite the opposite: it is a not wanted fact, which ought to be replaced by a more preferred one. The distinction between facts and values is - in its essence - an axiological operation and consists in negative meta-valuation of actually existing values, see (Wawrzyniak 2000: 268-277)

${ }^{8}$ See (Ossowska 1966: 72-83, 126-142, 147-167 ), (Znamierowski 1957: 22-228, 391-393)

${ }^{9}$ (Searle 1969: 177-178, 182)

${ }^{10}$ The promise is always made from the TS-level (see the footnote num. 6) embodying cultural conventions, so even if a particular speaking subject is insincere, the promise itself is valid and binding. 
to institutional facts, proves that J. Searle could not overcome the limitation on the realm of values to the sphere of human cultural activity.

Norms (ought-propositions), as linguistic creations, do not generate their validity themselves. The axiological binding force of a norm results from its origin in value, whereas the validity of thetic norms is conditioned by cultural imprinting or forcing under the threat of punishment for disobedience to them. Both the axiological and thetic binding force (imperativeness) of norms is of extra-linguistic origin. The axiological, thetic, and logical validity of norms are three different modalities of validity, of which only the axiological one is peculiar to moral discourse. The logically correct inference of a norm does not itself make for the moral validation (justification) of this norm. The type of validity of a norm depends on the axiological status of its origin (premises) and content. The means of argumentation for or against a norm is crucial.

Axiological (i.e. referred to value preferences) as well as moral problems are not solvable by formalized languages (e.g. modal logic systems), because they are not reducible to the issue of adherence to logical discipline of reasoning. There arises then the necessity to create such a language of axiology and meta-ethics which would render the real (i.e. axiological and not secondary-deontological) origin of validity (binding status) of moral norms. The metaethics of radical neonaturalism justifies norms - not rejecting, however, the device of formal logic as an linguistic code for the introduction of moral postulates into social circulation - also through the reference to extralinguistic and non-institutional brute valued facts (e.g. biological ones).

Searle identifies valuation proper, or a unique emotional process, with "valuations" as they are understood in logic or economy, as well as with the usage of evaluation-making predicates ${ }^{11}$. The axiological understanding of logical, or linguistic operations allows him to "find" the solution to the naturalistic fallacy not having to get conceptually beyond the practice of social use of language. The usage of subject complements or adverbials, which sound and are read identically in logic, epistemology, economy, praxeology, aesthetics or moral discourse, creates an appearance that the meanings as well as functions (illocutionary force) of these expressions remain unchanged in those particular contexts, which, in turn, confirms a false conviction that a system of a modal (especially deontic) logic embodies the "logic" of the valuation process as such. J. Searle recognized too wide a range of similarly sounding phrases as utterances reporting valuation proper.

There is such a significant degree of autonomy of usage itself attributed to speech that it creates its own realm of abstract semantic references, which is conducive to recognizing the rules of competent usage of a language as laws ruling the spheres of reality of which explanation is performed in this language. It seems as if J. Searle was under the delusion that the language of axiology has its own universal semantics, and that particular terms do not change their meanings and functions when the extralinguistic contexts of their usage is changed. While focusing - in his criticism of the dogmatic identification of usage with meaning (which was claimed by the postWittgenstein linguistic philosophy) - on illocutionary differences of the usage of words, Searle absolutized the category of meaning. He believed that the naturalistic fallacy fallacy is of purely lingusitic nature and consists in confusing the difference of illocutionary force (ways of use or functions) of utterances with the difference of their logical status (truth conditions or meanings); the latter makes the implication from descriptive proposition to a normative judgment really impossible ${ }^{12}$.

I think that language itself is not a sufficient and even proper realm for the solution of the isought problem, because the issue of deduction between propositions, differing in logical status, does not render the ontological particularities (modalities) of the states-of-affairs denoted by these propositions. Empirical reality is too complex for systems of formalized languages to reconstruct its status quo. In particular, language itself does not value, that is to say, it does not create

\footnotetext{
${ }^{11}$ For the ontic status of valuation see (Wawrzyniak 2000: 84, 93-101, 211-221)

12 (Searle 1969: 42-50, 132-136)
} 
the valuableness of anything; neither do logical operations generate oughtness as such; they only introduce duties (in the form of normative judgments) into social consciousness. Evaluation (which is a linguistic act) cannot be identified with valuation (which is a spiritual operation sui generis). An evaluative statement only reports or transfers the results of valuation, which does not have to assume a form of linguistic expression. Telling the truth is an act of actualization of the value of truth by means of a linguistic act, but the act itself does not create the valuableness of the truth.

The radical version of neonaturalism differs from the position of Searle in claiming that the naturalistic fallacy fallacy (NFF) is of extralinguistic nature and in looking for the possibility of deriving ought-conclusions from is-propositions (existential value-judgments and evaluations), which is to be found neither in the semantics of ethical terminology nor pragmatics of normative discourse but within the sphere of the ontology of values. I think that the NFF and methodological difficulties connected with normative reasoning are caused by: (1) the conceptual dualizing of Being into the separate sub-spheres of real facts and abstract-ideal non-realities called "values" ${ }^{13}$; and (2) the ontological interpretation of formalized language, consisting in the identification of principles of logical inference both with the real processes of valuation and the human acts of conscience-determined committing oneself.

\subsection{G.E. Moore's standpoint}

The so-called naturalistic fallacy (NF) proceeds on two levels: the ontological analyzed by G. E. Moore, and the linguistic (logical) one indicated by David Hume. Moore asserted that no semantic equivalence of ethical and empirical terms existed due to the difference of ontological status of qualities that were denoted by these two types of terms. This was a consequence of the extreme abstract realism of the Moore's axiology within the ontological dualism of facts and values ${ }^{14}$. If so, then Moore also recognized certain non-natural facts (real beings) as axiological qualities, and therefore he himself did not avoid the ontological mutation of what he called NF, and what W. Frankena named "moralistic fallacy", meaning a conceptual operation performed by Moore, the one consisting in making substance or actual being of pure normativity (resp. valuableness) ${ }^{15}$. It seems that in Moore's ontology, the valuableness (resp. oughtness), or goodness/badness - understood as a simple, indefinable property, irreducible to its empirical correlates - becomes a purely logical, Pythagorean-like category.

G.E. Moore suggests some approximations of the essence of NF:

(i) the identification of empirical attributes of good objects with the quality denoted by the "good";

(ii) the equation (reduction) of the normative quality (resp. intrinsic value) denoted by the adjective "good" and real - empirical or metaphysical - properties which are not normative in themselves;

(iii) the confusion of non-natural objects (resp. qualities) with natural ones;

(iv) the identification of what is simple, like the denotation of the "good" with the complex state-of-affairs like "conducive to the survival of a species" or "supposed to be good by the majority of rationally thinking people".

The above-mentioned ontological distinctions generate:

(v) the impossibility for ethical qualities (normative as well as simple) be defined in non-ethical terminology (e.g. in terms of natural sciences, social sciences or theology) which can only denote sub-universe of non-normative facts;

\footnotetext{
13 (Nozick 1981: 535-539)

${ }^{14}$ Let us note that naturalists and metaphysicians commit the naturalistic fallacy only from the perspective of the ontology assumed by the Moore's intuitionism. They themselves remain coherent while defining ethical terms within their own ontologies. (Moore 1956: 61-64) (Frankena 1967: 59-60)

15 (Frankena 1967: 61)
} 
A final result is:

(vi) the impossibility of deducing ethical (normative) conclusions from the premises not referred to the subuniverse of values (oughtness)

While analyzing, by means of analogy, the definitional status of "good", "yellow", "pleasant" and "supersensible (eternal) reality" Moore finds that "even if the quality denoted by 'good' were a natural object, that would not alter the nature of the fallacy...a whit" as well as that "to be good" does not mean "to have supersensible properties" 16 . It seems, therefore, that the NF, which can more exactly be called a "a trap of realism", can be understood as a definist fallacy consisting in defining or explaining a sphere of experienced reality by means of language and laws belonging to and fitting a nomologically different range of Being. However, the definist fallacy results from the ontological restriction, consisting in identification of the quality denoted by the "good" with a unique normative substantive being ${ }^{17}$. Within the framework of Moore's ontology, the defining of axiological (normative) categories in semantically strange terminology must reveal the lack of translatability.

From the neonaturalistic perspective the "location" itself of values either within the empirical (sensually detected or theoretically reconstructed) world or supranatural reality as well as the intuitionally perceived mental universe neither prevents the NF nor leads to it. It is so because this fallacy is, in its essence, the fallacy of metaphysical and, in consequence, definitional and methodological reductionism. An example of the fallacy is the reduction - rooted in positivistic paradigm - of moral dilemmas to formal-logical issues or verbal operations. And if we a priori divide Being into sub-realms of facts and values - as G.E. Moore does - then the logical aspect of the NF will be the common consequence of such a division. But if we did not perform such an ontological operation, then the is-ought entailment will be logically possible, provided the existential judgments of normative empirical facts are employed as necessary premises of imperative conclusions (orders, prohibitions, prescriptions).

\section{A neonaturalistic proposal}

Within neonaturalistic ontology, values have the status of particular facts, which means that not every fact is valued. Normativity is attributed to no other universe than the natural one, because values and facts belong to the same nomological order. A fact can be normative, for ontological difference (the way of being) does not mean ontic one (referred to physical characteristics). The synonymy (and not only material or formal equivalence) occurs between propositions containing the terms which denote empirical normative facts and the ethical judgments, but not between normative (e.g. moral) propositions and the statements of non-normative facts. Ethical terms can have empirical or theoretical semantic references, for normativity (valuableness) is the unique way of being of the empirical, and, as such, can be defined - as for its attributively determined existence - in descriptive is-statements.

Not every is-ought derivation is committing the naturalistic fallacy. The denotation of an ispremise, or the existential judgment of a fact on account of which a given norm - concerning the change or keeping-on this factual state-of-affairs - is formulated, is crucial. Neonaturalism recognizes as values such empirical states-of-affairs which comply with the Moore's "open question argument", and thus this philosophical perspective enables the participants of normative discourse to formulate axiological judgments - especially evaluations which represent a particular kind of normative is-statements - by means of empirical predicates and to derive norms on the basis of these judgments. It is so because they are judgments of particular, normatively

16 (Frankena 1967: 56-57), (Moore 1956: 10, 12-13, 120-125); let us notice that in Moore's meta-ethics, axiological definitions are analytical as well as designative (projective), and they do not treat of the existence itself of good/bad objects.

${ }^{17}$ In the reasoning quoted by W. Frankena - <if [a] pleasure is sought by all men, and [b] what is sought by all men is good (by definition), therefore [c] pleasure is good $>$ - in order to prove that the NF is not a logical one, the second premise involves the NF in definitional sense; (Frankena 1967: 54) 
relevant facts, or of what ought - from the very definition of a value (resp. the state of oughtness) to come (resp. not to come) into real being and to last. Therefore they have a logical status of judgments of obligation and lead to ought-instructions, or norms and prescriptions. These are values which generate and determine obligations. In neonaturalistic perspective, the ontological profile of the world, especially the relational valuability of Being, determines practical normative solutions, including the methodological discipline of reasoning to be applied in moral discourse.

A simplified scheme $\langle 1-5.1\rangle$ of an is-ought reasoning concluded with a norm could seem as follows:

1. $<X$ is obligatory (is ordered) to be actualized or $X$ is obligatory (is banned/prohibited) not to be actualized (not to come into real being) if and only if $X$ is a value>.

2. $\langle X$ is $\alpha / \neg \alpha$ and there is $\mathrm{good} / \mathrm{bad}$ to be (not to be) $\alpha / \neg \alpha>$. This proposition is a conjunction of the predicate " $X$ is $\alpha$ " and the existential evaluative statement "it is $\operatorname{good} / \mathrm{bad}$ to be $\alpha / \neg \alpha "$.

3. <If $X$ is $\alpha / \neg \alpha$ ), then $X$ is a positive/negative value>.

Where ' $\alpha$ ' is denoting any empirical attributes or state-of-affairs that used to be praised/reproved (e.g., just, clever, noble, disgusting, nasty, criminal) in a given society, whereas ' $\neg a$ ' denotes the absence of these attributes. If ' $\alpha$ ' is accepted, then ' $\neg \alpha$ ' is not accepted (is negatively indifferent") and vice versa.

4. Any set of descriptive propositions which provide good reasons for a normative conclusion. In particular, they can be the propositions of the, e.g. feasibility, profitability or rightness ("right" is here meant as "the best of all possible options") of a valued $X$ that is to be actualized, as well as the assertions of necessary means/devices to act efficiently for the sake of $X$. For example: $\langle X$ is accomplishable (resp. unaccomplishable) as $\alpha\rangle$.

5. Therefore: for every agent recognizing premises $\langle 1-4\rangle$ it is obliged to realize (keep on existing) / not to realize $X$. This is a final norm which meets the requirement of universalizability addressed to ethical judgments of obligation.

5.1. There follow bans or orders to change / to keep on the state $X$, which are addressed to individual agents: <you ought/ought not to act as it is indicated in the content of 5>. From the neonaturalistic perspective, the "committing" of the analyzed "fallacy" seems to be a condicio sine qua non for the normative ethics being constructed. The real reasons of thinking that formal logic is the only instrument of moral justification are cultural preferences. Behind such a defense for formal-logical validation within the sphere of morality the identification of logic with a proper - because typically human - language of moral argumentation is hidden. By defending the purely logical nature of moral justification Homo sapiens defends human language as the only means of cognition and communication of values. Language is comprehended as a product as well as a symbol of human culture, which is supposed - in common conviction to be the only realm of values. The going out of a system of formalized language in the procedure of normative justification is supposed to be a hardly acceptable leaving (or even the betrayal of) the human species' culture. Through the claiming of the impossibility of is-ought inference, humans defend their self-distinguished status in evolution, or defend themselves against moral evaluation of their own species' stay on the Earth. The naturalistic fallacy fallacy is a metaphysical fallacy, consisting - in its axiological essence - in setting the world of nature against the world of culture, or in restricting the realm of values to cultural phenomena, which as such is generated by speciesism. 


\section{Bibliography}

Austin, J. 1993. Mówienie i poznawanie (Philosophical Papers; How to Do Things with Words). Warszawa: PWN. Ehrlich, S. 1995. Wiażace wzory zachowania (The Binding Patters of Conduct). Warszawa: PWN.

Frankena, W.1967. The Naturalistic Fallacy. In: Ph. Foot (ed.), Theories of Ethics, London: OUP. pp: 50-63

Hare, R.1967. The promising game. In: Ph. Foot (ed.), Theories of Ethics. London: OUP. pp: 115-127127

Hume, D. 1952. Traktat o naturze ludzkiej (The Treatise on Human Nature). Kraków: PAU.

Moore, G.E.1922. The Conception of Intrinsic Value. In: Philosophical Studies. London: CUP. pp: 253-275

Moore, G.E. 1956 (1903, 1922). Principia Ethica. Cambridge: CUP.

Nozick, R.1981. Philosophical Explanations. Oxford: Claredon Press.

Ossowska, M.1966. Podstawy nauki o moralności (The Foundations of the Science of Morals). Warszawa: PWN.

Searle, J. 1969. Speech acts. An Essay in the Philosophy of Language. Cambridge: CUP.

Wawrzyniak, J. 2000. Teoretyczne podstawy neonaturalistycznej bioetyki środowiskowej (The Theoretical Foundations of Neonaturalistic Environmental Bioethics). Poznań: IF UAM Scientific Press.

Wawrzyniak, J. 2005. Aksjologiczność i etyczność nauk społecznych (The Axiological and Ethical Status of Social Sciences). In: Zamiara, K. (red.), Etyczne aspekty badań społecznych (Człowiek i Społeczeństwo XIV). Poznań: UAM Scientific Press. pp:59-76

Wittgenstein, L. 2000. Dociekania filozoficzne (Philosophical Investigations). Warszawa: PWN.

Znamierowski, Cz. 1957. Oceny i normy (Evaluations and Norms). Warszawa: PWN. 